\title{
How worthwhile is it to maximise customer satisfaction in public transport service contracts with a large captive user base? The case of South Africa
}

\author{
Mathetha Mokonyama ${ }^{\mathrm{a}, *}$, Christo Venter ${ }^{\mathrm{b}}$ \\ a CSIR, P O Box 395, Pretoria, 0001, South Africa \\ b University of Pretoria, Private Bag X20, Hatfield, 0028, South Africa
}

* Corresponding author. E-mail address: mmokonyama@csir.co.za (M. Mokonyama).

\begin{abstract}
A b s t r a c t
While improved service quality is critical for improved patronage of public transport services, in markets characterised by large proportions of captive public transport users, typically found in developing or emerging economies, the marginal benefits of improved service quality are not apparent. For cost-conscious public transport operators, therefore, it may be more convenient and logical to keep service improvements at a bare minimum, or to cut services altogether, in order to reduce operating costs. As a follow-up to Mokonyama and Venter (2013), the paper uses historical financial and patronage data from existing bus contracts in South Africa and a conjoint-analysis based behavioural model to estimate the budgetary implications, and marginal benefits, of specifying service quality in public transport contracts. This is especially relevant in an environment like South Africa, in which authorities seek some formulation of Pigouvian subsidy oriented transport policy. It is shown that the marginal benefits of improved service quality can be significant relative to the business as usual alternative. The non-linear response surface characterising the relationship between probability of using a service and the quality of the service implies that increased satisfaction of both captive and non-captive users produces disproportionately higher benefits for both and society.
\end{abstract}

Keywords:

Public transport service

quality Captive users

\section{Introduction}

Captive public transport users make use of particular public transport services for reasons that include being unable to afford alternative transport modes, psycho-physical limitations, and regulatory restrictions (Jacques, Manaugh, \& El-Geneidy, 2013; Paulley et al., 2006). In some sectors, such as telecommunication and banking, customers may become captive to services for reasons that include perceived high cost of switching to alternatives (Rowley, 2005). The Department of Transport in South Africa distinguishes between two types of public transport captive customers: (i) survivals-who are captive to a single public transport mode, and (ii) sensitive-who, while can only afford to use public transport, they can nonetheless afford to use the best available public transport mode, for example a high end bus service instead of a cheaper dilapidated commuter train service. Nonetheless, both these categories of captive users were projected by DoT (1998) to be a half of the entire South African urban passenger transport market share in by 2020 .

By virtue of being captive public transport users, these customers may become susceptible to receiving poor services given their characteristic inelastic demand (Grisé \& El-Geneidy, 2017; Rose, Racadio,
Martin, Girard, \& Kolko, 2017). In Colombia, Marquez, Pico, and Cantillo (2018) finds that captive users are willing to compromise their personal safety through the use of cheaper but illegal and very unsafe "motorcycle taxis". Public transport captive victims of sexual harassment also continue to use public transport services, although at reduced rates (Buckley, 2016). For a cost-conscious public transport operator, therefore, it may be more convenient and logical to keep service improvements at a bare minimum, or to cut service altogether, in order to reduce operating costs. Garrett and Taylor (1999), and Walker (2008), describe this as an inequitable and economically inefficient approach, especially if the purpose of service cuts to existing (captive) users is to fund improvements in order to attract choice riders to increase patronage. Moreover, the heterogeneity and dynamic nature of the composition of a captive market (Bordagaray, dell'Olio, Ibeas, \& Cecín, 2014; Verbich \& El-Geneidy, 2016), as well as the possible interaction effects with all other user segments, warrants an improved understanding of longer term impact, particularly financial impact, of improved service quality on services with a large proportion of captive users, especially in an environment where operators may be driven by short-term commercial interests. Social capital theory also advocates improved valuation of non-tangible assets such as trust and social 
cohesion emanating from the sharing of spaces with the use of public transport services (Currie \& Stanley, 2008; Stanley, Stanley, VellaBrodrick, \& Currie, 2010). In this context customer satisfaction can also be considered an asset requiring improved valuation (Ilieska, 2011).

The paper estimates the budgetary implications, and marginal benefits, for specifying service quality in public transport contracts where a large proportion of users is made up of captive users. It answers the question: How worthwhile is it to maximise customer satisfaction for services with a large captive customer base? Analysis in the paper is limited to a typical subsidised bus service in the urban areas of South Africa, in the context of authorities seeking some formulation of Pigouvian subsidy oriented transport policy in order to transcend the prevailing public transport subsidy objective of just reducing transport costs for the labourers displaced by apartheid policies (Hunter van Ryneveld, 2014).

\section{Background}

Customer satisfaction is judgement exercised by a customer, following a service encounter, in respect of the extent to which the service fulfilled customer needs or expectations (Grigoroudis \& Siskos, 2010). Be they tangible or non-tangible, the perceived performance of service attributes by the customer is used as a basic input in the measurement of customer satisfaction (Ramaswamy, 1996; Wirtz \& Bateson, 1995), and the actual relationship between service attribute performance and customer satisfaction, even for public transport services, is non-linear (Mokonyama \& Venter, 2013).

While customer satisfaction has been shown to be positively correlated with improved business performance, mainly due to increased patronage and customer loyalty, customer dissatisfaction on the other hand may lead to outcomes other than refusal to use the service again. Artis (2004) shows, through the matrix presented as Table 1, that once dissatisfied, not all customers resort to the switching of service providers. Rather, customers react on the basis of a combination of the dissatisfied customer's chosen coping tactic and the customer's response goal. For example, a combination of "external self-directed coping strategies" and "retaliation goal" results in private vindictive behaviour, which could be exhibited, for example, by service captive customers. The generic model by Artis (2004) is especially relevant for identifying possible reactions from captive public transport customers. Although not directly quantifiable, the manifestations of customer dissatisfaction as shown in this model are illustrative of the inherent negative impact dissatisfaction has on both the service provider's business and the customer's well-being.

A framework to estimate the value of customer satisfaction, particularly for services with large captive users, is necessary to assess the marginal benefits of service improvements. This approach could also facilitate the estimation of the asset value of customer satisfaction.

\section{Case study}

The case study comprises a selection of subsidised bus contracts in the urban areas of South Africa. In their current form, subsidised bus contracts in South Africa have roots in the 1996 White Paper on National Transport Policy which required all previously subsidised bus services (subsidised mainly to reduce commuting costs for displaced workers under the apartheid regime) to be put out on competitive tender (Walters, 2014). Notwithstanding various legal, institutional and operational problems associated with the contracts, to date, 66 contracts are tendered, 10 are negotiated and 68 are under interim arrangement for competitive tendering (Walters, 2014).

Buses are the only mode of public transport that are delivered in terms of contracts, and these contracts make provision for the specification of public transport service quality. These bus contracts are currently subsidised to the tune of R5.7 billion (US $\$ 0.5$ billion) per annum, amounting to $10 \%$ of the total annual budget for the national

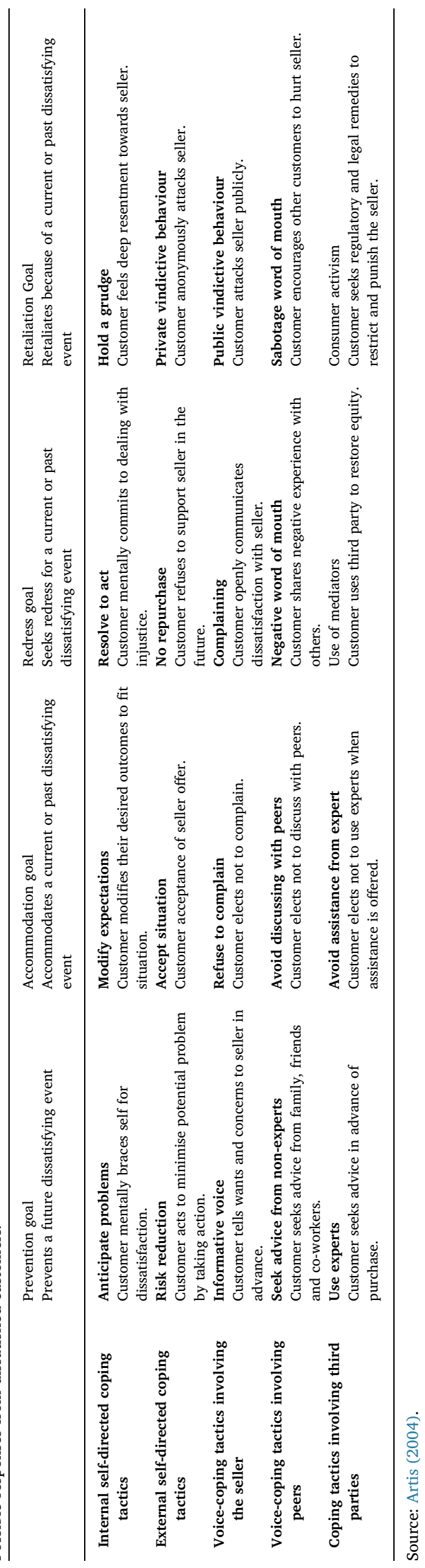


Table 2

Customer satisfaction binary logit model parameters.

\begin{tabular}{llll}
\hline Respondent category & Coefficient & Constant & Nagelkerke $\mathrm{R}^{2}$ \\
\hline User & 1.08 & -4.47 & 0.76 \\
Non-user & 1.54 & -9.37 & 0.84 \\
\hline
\end{tabular}

Department of Transport (National Treasury, 2017). On a typical day, up to $20 \%$ of households in South Africa have at least one member making use of a bus service (StatsSA, 2014). Other public transport modes include trains (also subsidised but not contracted) and minibus taxis (not subsidised).

The use of contracts to manage public transport services in South Africa, specifically subsidised bus services, was formally introduced in 2006 through model contract documents (DoT, 2006). The South African model contract documents make provision for the monitoring of contractor performance, with a specific focus on service reliability, punctuality, driver quality, bus availability, vehicle quality, safety, revenue protection, contract compliance, and user (customer) satisfaction. Customer satisfaction itself is supposed to be measured through surveys that are carried out annually, in which a sample of customers are asked to rate the service in terms of information quality, safety, security, cleanliness, reliability and staff behaviour. Operators are required to achieve a target of $95 \%$ overall customer satisfaction. The contractor's historical performance with regard to customer satisfaction is used when the contract is due for renewal, where good performance counts in favour of the contractor. Other than this consideration, customer satisfaction is not used in any other way. Nonetheless, South Africa also has a piece of legislation referred to as the Consumer Protection Act (RSA, 2011), which provides consumers, including public transport users, with some recourse against service providers for poor services. In terms of the act, the consumer has the right to claim against the service provider for loss suffered, including economic loss.

\section{Approach}

A rating-based conjoint analysis experiment was carried out in metropolitan areas of South Africa, on a sample of 64 respondents, yielding 1152 observations of service package ratings from 18 ratings profiles, which was the minimum required for an orthogonal design.
Usually, about 30-60 respondents are necessary for conjoint analysis experiments for investigational work or development of market hypotheses (Orme, 1998). The respondents comprised 40 public transport users (of a train service referred to Tshwane Business Express or TBE), who have access to personal cars (choice users), and another group of 24 non-users of public transport, using their personal cars and sharing similar work-based trip origins and destinations with the first group of public transport users. At the time, TBE was the only public transport service in South Africa which had almost all of its customers as choice users.

The actual experiment is reported in more detail by Mokonyama and Venter (2013). In brief, however, respondents were requested to rate different public transport service packages that were defined in terms of service attributes that include reliability, security, and payment convenience. They were also asked to indicate how likely they were to use a service with the given set of service attributes, which in turn was used to estimate probability of travel mode choice. The conjoint model parameters were estimated using ordinal multiple regression, and it was found that statistical significance varied across attribute levels, users and non-users, as well as across attributes. Overall, the attributes with across the board statistical significance were reliability, security, and cost. While relatively old, the experimental results remain relevant because the nature of service offerings remains virtually the same, but questions of how to specify quality in public transport service contracts are only now emerging. Nonetheless, continued monitoring of the market will help service reforms to be more demand responsive.

Binary logit models were fitted to the relationship between the service satisfaction rating and the decision made by the users and nonusers to either use TBE or use their personal cars for commuting, in the generalised form: $P(x)=\frac{e^{(B x+k)}}{1+e^{(B x+k)}}$ where $x=$ value of predictor variable $x, B=$ coefficient, $k=$ Constant, and $P(x)=$ Probability of an outcome $x$. The model parameters for both TBE users and non-users are summarised in Table 2 . The relationships are significantly strong with Nagelkerke $\mathrm{R}^{2}$ ranging between 0.76 and 0.84 for users and non-users respectively. Based on these model parameters, Fig. 1 shows curves fitted to the relationship between satisfaction rating and the probability of a user being retained on TBE or a non-user being attracted to TBE. The relationship shows, for example, that existing users are easier to satisfy than non-users for every marginal improvement in service quality. As shown in the next section, this relationship can be used to

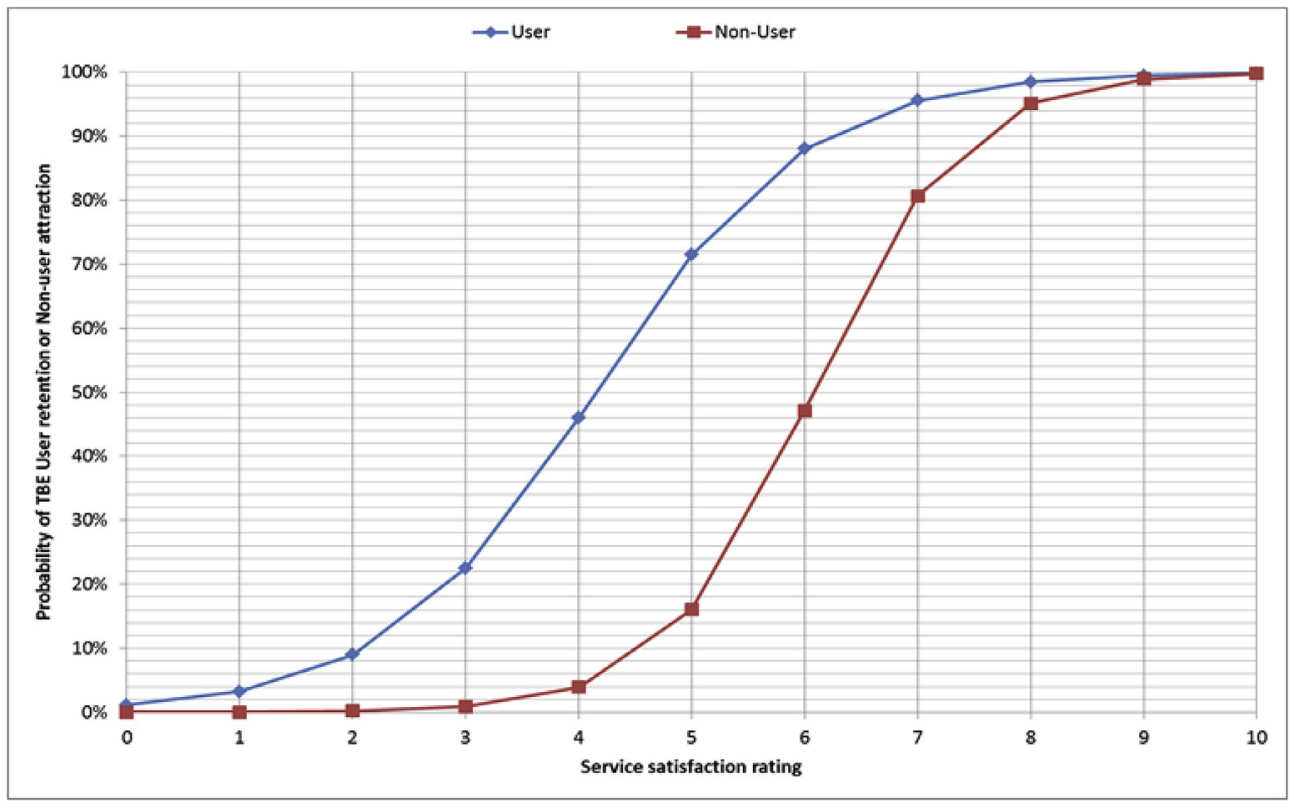

Fig. 1. Relationship between perceived service quality and probability of retaining existing choice users and attracting non-users. 


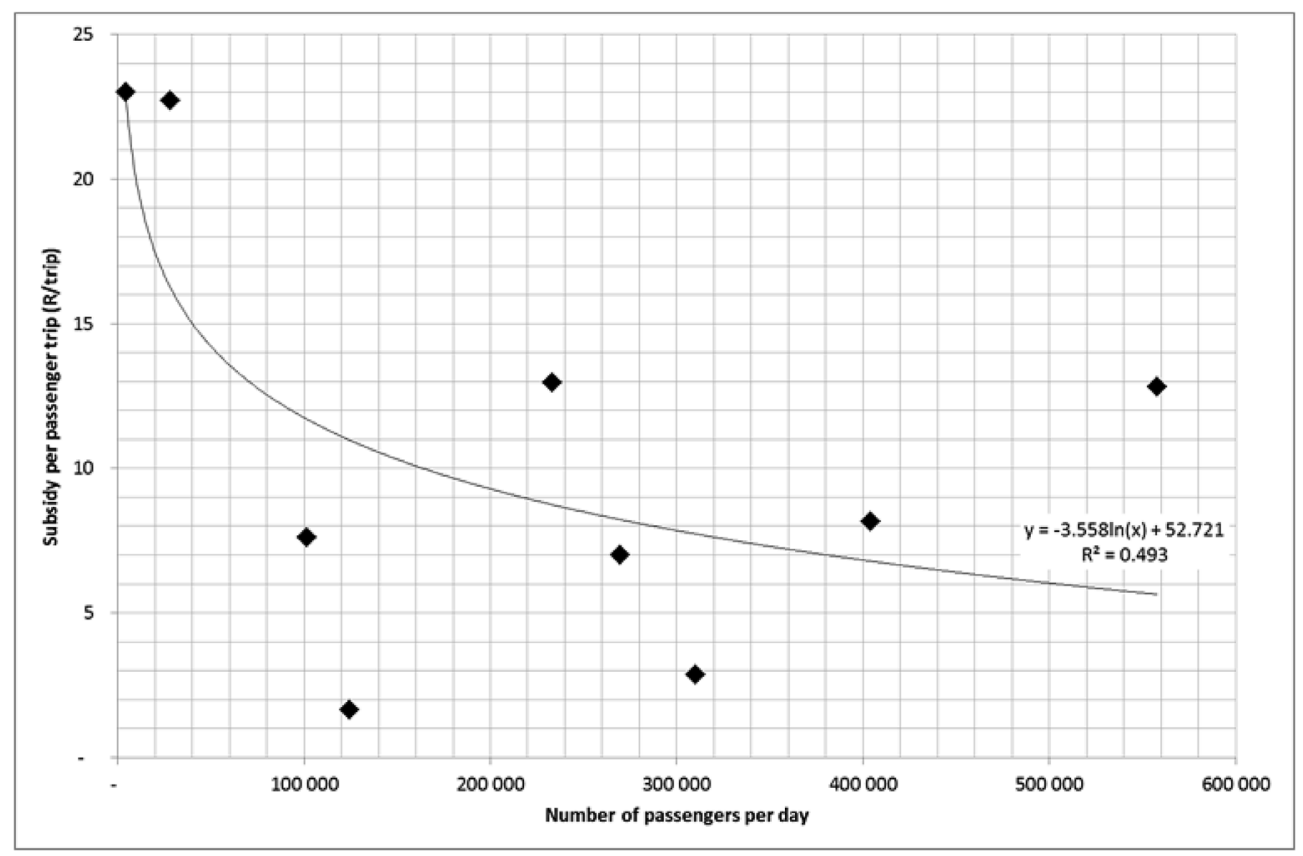

Fig. 2. Estimated relationship between passengers serviced per day and subsidy per passenger trip.

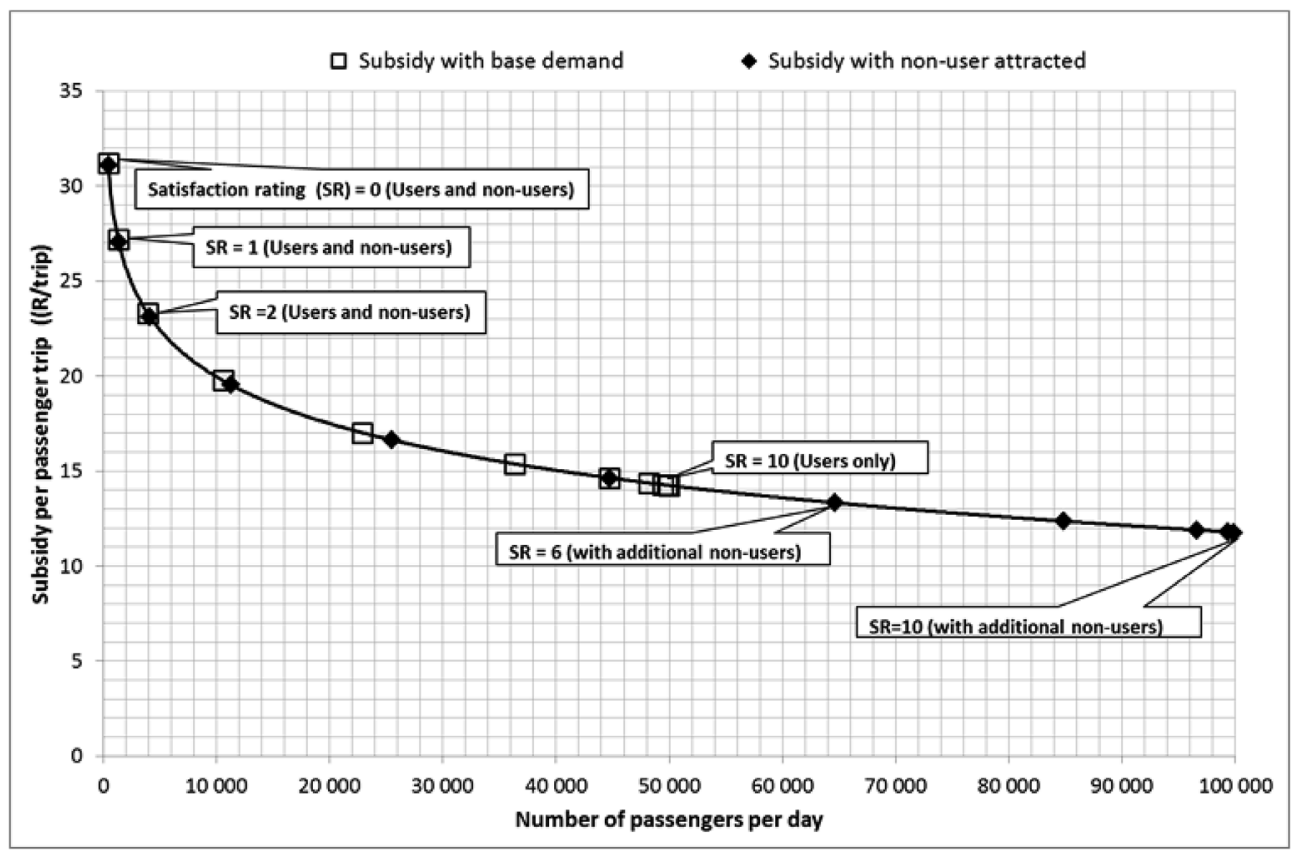

Fig. 3. Subsidy and the levels of customer satisfaction.

estimate the expected patronage increase (or decrease) associated with a marginal increase (or decrease) in service quality, assuming that stated likelihoods are true reflections of usage probability.

\section{Analysis of financial implications of incorporating service quality}

Through maximising social capital (Stanley et al., 2010), public transport has the propensity to increase community prosperity, which is defined in terms of economic, environmental and social externalities accruing to society (Lowe, 2016). However, the failure to fully reflect such externalities in the price of using public transport, including through Pigouvian subsidy, remains a fundamental flaw in the market. This is particularly true in developing countries where negative transport externalities that are positively correlated with climate change may even have disproportionate impact on climate-sensitive natural resources. The impact of improved public transport service quality on land values and sustainable land uses in developing countries has also been proven (Cervero \& Kang, 2009). However, through an extensive literature review, Kwan and Hashim (2016) show that integrated co-benefit analysis on mass public transport has received little attention. The availability of data and associated methods to quantify such externalities is a challenge (Currie \& Stanley, 2008; Pearce, 1978), and may be contributing to the status quo. From a narrow perspective, the paper estimates financial benefits that could be derived from improved public transport service quality, in a market characterised by high proportions of captive public transport users. Further research would need to address other forms of co-benefits related to improved 


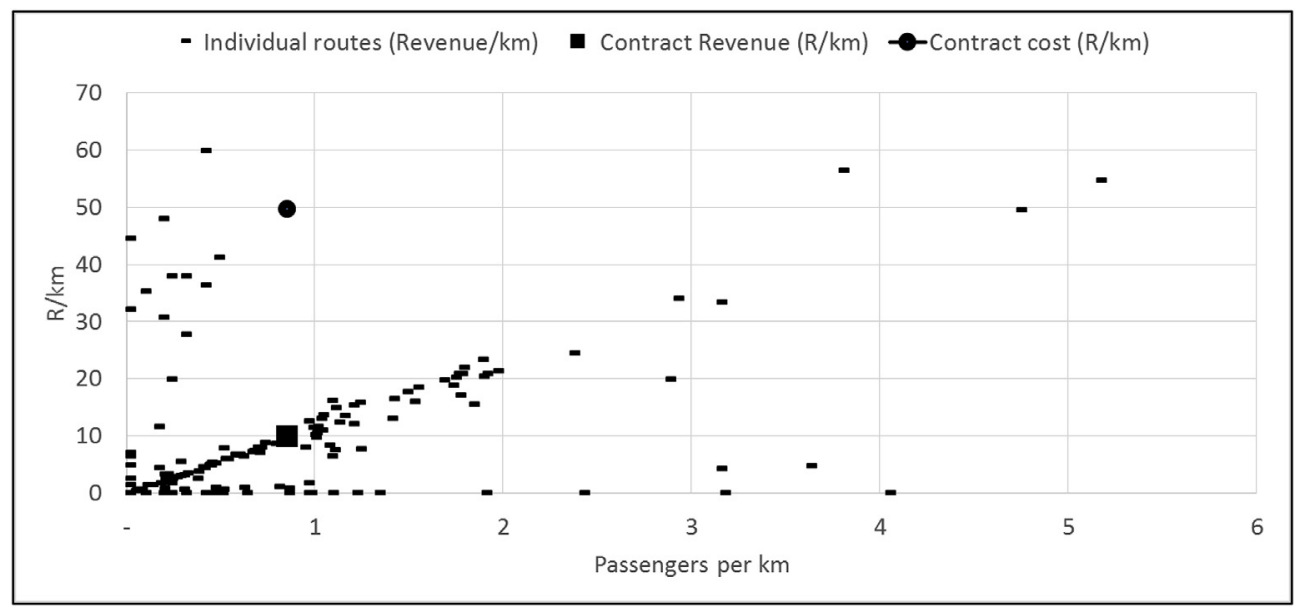

Fig. 4. Financial performance metrics for a typical subsidised bus contract in a South African city.

public transport quality.

Based on the relationship depicted in Fig. 1, as well as historical transactional data for selected subsidised bus services in South Africa, inferences are made on patronage-based financial implications of service quality for captive public transport customers. The reason for making inferences using non-captive customers is because such a relationship for captive customers would not be practical to produce. Since captive users have no other travel options, therefore, they are assumed insensitive to service quality (for the purpose of the argument). However if public transport services serve both captive and noncaptive users, then service quality improvements would attract new non-captive passengers, and the size of this response can be estimated. The resultant extra ridership would impose additional benefits that also accrue to the captive riders. As shown by Fujii and Kitamura (2003) the ridership of historically non-captive users can be sustained in the long term once they experience the convenience of using the service. The approach followed here, therefore, effectively explores ways of estimating the asset value of customers, be they captive or not.

Fig. 2 shows, for subsidised bus services in South Africa, the relationship between passengers carried and subsidy per passenger trip, where each point represents a cluster of subsidised bus contracts in each of South Africa's nine provinces (US\$1 $\approx \mathrm{R} 12$ ). Using a least squares curve fitting, the relationship is approximated by a logarithmic relationship shown in Fig. 2 with $\mathrm{R}^{2}$ of 0.5 , implying that the number of passengers per day explains only half of subsidy levels. Other factors such as management practices, regional labour prices, fare structures, vehicle dead kilometres per contract, vehicle occupancies, and trip lengths, while not accounted for, may be having a significant impact on the resulting subsidy levels. However, due to various legacy issues (Walters, 2014), very little is known about the operational attributes of these contracts apart from their financial accounting characteristics. Using the relationship from Figs. 1 and 2, Fig. 3 is constructed on the basis of having a synthetic population consisting of 50000 choice users already using public transport and another 50000 not using public transport but willing to do so if it meets their requirements. Each point in Fig. 3 represents for each different customer satisfaction ratings, from 0 to 10 , the relationship between passenger numbers and the amount of subsidy per passenger in the context of the socio-economic characteristics of the observed respondents. Different socio-economic contexts may yield different curves.

Satisfaction level 0 is associated with high levels of subsidy because the number of users is at a minimum to cover-operating costs. Increased satisfaction results in increased patronage and reduced subsidy payments per passenger trip, which in essence is some extension of the Mohring effect (Gómez-Lobo, 2011; Mohring, 1972), albeit often used to justify increased subsidy to improve public transport services. The
Mohring effect states that as demand for public transport increases, [and] optimal frequencies also increase, thus diminishing waiting times for all users, [and making public transport more attractive], this generates a positive externality on existing users and social marginal costs [given the reduced use of more individualised private cars]. For existing users in this specific case, when the satisfaction levels increase the amount of subsidy per passengers also reduces to an extent that a service rated at satisfaction level 10 is equivalent to halving of subsidy per passenger (for the same infrastructure capacity), because there are more users to offset operational costs. When a greater number of nonusers is attracted through improved perception of service quality, the subsidy payment per passenger at satisfaction rating of 10 , for example, is equivalent to reducing subsidy per passenger by two thirds. Such savings could be used to further finance accessibility for low income captive customers.

Fig. 4 shows financial performance metrics of a typical subsidised bus contract in a South African city, in which almost all users are captive to the service. A number of observations are made:

- The passengers per km metric tends to be low. This is because most of the trips are made from historically isolated settlements and destined to the centre of cities, with very little passenger boarding/ alighting activity along the routes.

- The level of subsidy on these contracts can be as much as five times the revenue. Such a relatively high level of subsidy puts a strain on the country's finances and reduces the capacity to expand the network, especially for cities experiencing large volumes of in-migration of low income households. Any opportunity to reduce subsidy commitments per passenger trip may therefore improve the capacity to extend the service.

In countries with severe socio-economic backlogs like South Africa financial efficiency gains would be welcome. Apart from public transport efficiency gains, other benefits, although not included in this analysis, include potential savings from reduced household transport costs, reduced expenditure on energy imports, and emission reductions. However, the cost savings would be directly proportional to the number of trips that would have otherwise used individualised travel. An increase in passengers per $\mathrm{km}$ and a reduction in subsidy would certainly increase the financial viability of the contract depicted in Fig. 4.

In order to relate the above results to actual operations, Table 3 presents operational data from another operator, but whose routes are mainly located within the core of a city, with most of its users also being captive. The table shows parts of the service's income statement and other service performance attributes. For example, with annual revenue of over R62 million, the service has a cost recovery ratio of 0.26 . Apart 
Table 3

Projected operator performance of with marginally improved service.

\begin{tabular}{|c|c|c|c|}
\hline \multicolumn{4}{|c|}{ Income statement (US\$1 $\approx \mathrm{R} 12$ ) } \\
\hline Item & & Actual Value (R) & $\begin{array}{l}\text { Scenario-based } \\
\text { values }(\mathrm{R})\end{array}$ \\
\hline \multirow[t]{3}{*}{ Revenue (R) } & Fare Revenue & 47757592 & 76412148 \\
\hline & Other income & 14322849 & 14322849 \\
\hline & Subtotal & 62080441 & 90734996 \\
\hline Major Operational & Vehicles & 45957146 & 45957146 \\
\hline \multirow[t]{3}{*}{ Costs (R) } & Licences & 3368223 & 3368223 \\
\hline & Fuel & 30076971 & 30076971 \\
\hline & Subtotal & 79402340 & 79402340 \\
\hline Major Overhead & Salaries & 55480494 & 55480494 \\
\hline \multirow[t]{12}{*}{ Costs (R) } & Overtime salaries & 7667000 & 7667000 \\
\hline & Service bonus & 4135561 & 4135561 \\
\hline & $\begin{array}{l}\text { Pension and } \\
\text { provident fund }\end{array}$ & 10602206 & 10602206 \\
\hline & Medical aid fund & 7097809 & 7097809 \\
\hline & $\begin{array}{l}\text { Depreciation and } \\
\text { amortisation }\end{array}$ & 11510965 & 11510965 \\
\hline & Cleaning services & 1700654 & 1700654 \\
\hline & Electricity & 2373684 & 2373684 \\
\hline & Buildings & 2042320 & 2042320 \\
\hline & Lease vehicles & 46689372 & 46689372 \\
\hline & $\begin{array}{l}\text { Other employee } \\
\text { allowances }\end{array}$ & 2439 & 2439468 \\
\hline & Subtotal & 151739534 & 151739534 \\
\hline & Other costs & 11753581 & 11753581 \\
\hline Total cost & & 242895455 & 242895455 \\
\hline Margin & & $(180815014)$ & (152 160 459) \\
\hline \multicolumn{4}{|c|}{ Other performance parameters } \\
\hline \multicolumn{2}{|l|}{ Passengers per annum } & 9096684 & 14554694 \\
\hline \multicolumn{2}{|c|}{ Operated km per annum } & 9025355 & 9025355 \\
\hline \multicolumn{2}{|c|}{ One-way network size (km) } & 2142 & 2142 \\
\hline \multicolumn{2}{|c|}{ Staff (filled vacancies) } & 380 & 380 \\
\hline \multicolumn{2}{|l|}{ Staff (all vacancies) } & 573 & 573 \\
\hline \multicolumn{2}{|l|}{ Number of buses } & 350 & 350 \\
\hline \multicolumn{2}{|c|}{ Fare revenue per km (R) } & 5.29 & 8.47 \\
\hline \multicolumn{2}{|c|}{ Total income per km (R) } & 6.88 & 10.05 \\
\hline \multicolumn{2}{|c|}{ Total cost per km (R) } & 26.91 & 26.91 \\
\hline \multicolumn{2}{|c|}{ Annual kilometres per bus (km) } & 25787 & 25787 \\
\hline \multicolumn{2}{|c|}{$\begin{array}{l}\text { Average passenger trips per vehicle } \\
\text { km }\end{array}$} & 1.01 & 1.61 \\
\hline \multicolumn{2}{|c|}{ Cost recovery ratio } & 0.26 & 0.37 \\
\hline \multicolumn{2}{|c|}{ Annual business cost per vehicle (R) } & 693987 & 693987 \\
\hline \multicolumn{2}{|c|}{ Total annual revenue per vehicle (R) } & 177373 & 259243 \\
\hline \multicolumn{2}{|c|}{$\begin{array}{l}\text { Annual revenue per staff (filled } \\
\text { vacancies) }(\mathrm{R})\end{array}$} & 163370 & 238776 \\
\hline \multicolumn{2}{|c|}{$\begin{array}{l}\text { Annual business costs per employee } \\
\quad \text { (filled vacancies (R) }\end{array}$} & 639199 & 639199 \\
\hline \multicolumn{2}{|c|}{$\begin{array}{l}\text { Annual revenue per staff (total } \\
\text { vacancies) }(\mathrm{R})\end{array}$} & 108343 & 158351 \\
\hline \multicolumn{2}{|c|}{$\begin{array}{l}\text { Annual business costs per employee } \\
\text { (total vacancies) (R) }\end{array}$} & 423901 & 423901 \\
\hline Annual fuel per vehi & e (Litres) & 10892 & 10892 \\
\hline Estimated annual pa & engers per vehicle & 22855 & 22855 \\
\hline Staff cost as a perce & age of total costs & $36 \%$ & $36 \%$ \\
\hline $\begin{array}{l}\text { Average vehicle fuel } \\
\quad \text { (Litres } / 100 \mathrm{~km} \text { ) }\end{array}$ & onsumption & 50 & 50 \\
\hline $\begin{array}{l}\text { City density (person } \\
\text { kilometre) }\end{array}$ & per square & 476 & 476 \\
\hline$\%$ of demand in pea & hour & $20 \%$ & $20 \%$ \\
\hline
\end{tabular}

from the actual performance figures, the table also estimates the operator's income statement for a scenario where passenger demand would be equivalent to attracting new passengers at a satisfaction rating of level 4 in Fig. 1, corresponding to the maximum peak capacity utilisation of the fleet. The size of the fleet as well as the operating costs under this scenario should not necessarily have to change because the same resources are being used, only better than was previously the case (assuming relative low cost of service improvements). In this scenario the service margin is reduced by $16 \%$ and cost recovery changes from
0.26 to 0.37 . The passenger trips per vehicle $\mathrm{km}$ performance metric increases from 1.01 to 1.61. All these changes result from a perceived performance rating of 4 out of 10 by non-users. The operator in this scenario makes an annual saving of R25.7 million (US\$2.1 million), which is equivalent to fully financing about 14 buses, and in this case increasing the fleet size by $4 \%$.

\section{Discussion}

The foregoing analysis shows that services characterised by a large proportion of captive users can benefit from improved service quality, although the extent of the benefits would be context dependent. Of significance is that even at relatively low perceived quality levels by non-users the benefits can be significant. The non-linear response surface characterising the relationship between probability of using a service and the quality of the service also implies that much higher service ratings would produce disproportionately higher benefits. However, due consideration should be made of the dynamic nature of the individual importance of service attributes that make up the entire service package, especially as perceived by non-captive customers in the light of competing alternatives.

The findings also open up the possibilities of using service quality models in the pre-planning of public transport service contracts. This would be in contrast to the predominant use of service quality measurements in the post-award monitoring of the contracts. In this way, service quality innovation to help maximise service patronage becomes an integral part of contract designs.

The estimation of financial benefits from improving service quality in services characterised by large proportions of captive users in this paper was done from a narrow perspective. Improved approaches to estimate such benefits should be the subject for future research. More fundamentally, further research should develop improved methods for estimating the true asset value of public transport passenger trips or a satisfied customer.

The results of the research presented are limited to South Africa as a case study. However, the problem associated with the neglect of captive public transport users is a global problem, which if untended, could trigger other bigger problems such as social unrest. This is because poor public transport service quality does not only result in the change of mode, as often depicted in transport literature. Other countries will benefit from investing in research to study the broader implications of improving service quality for captive public transport users in addition to choice users.

\section{Conclusions}

The management of public transport services through contracts between contracting authorities and public transport operators is a relatively new development in emerging economies like South Africa. The role and value of service quality in such contracts is not always apparent given that public transport services are mainly used by captive users. Consequently, captive public transport users are prone to receiving poor services given their characteristic inelastic demand. While increasingly poor services may not lead to the switching of services by captive customers, the many manifestations of customer dissatisfaction are illustrative of the negative impact that increased dissatisfaction has on both the service provider's business and the customer's well-being. Some of the manifestation of customer dissatisfaction include violent outcomes.

Through social capital theory it is apparent that improved valuation of non-tangible assets such as trust and social cohesion, emanating from the sharing of spaces with the use of public transport services, customer satisfaction can also be considered an asset, alongside economic, environmental and social externalities accruing to society. However, the value of this asset appears generally underestimated. However, the availability of data and associated methods to quantify such 
externalities remains a challenge, especially in generally data scarce environments found in developing countries.

The paper narrowly focused on the benefit of improving the overall service quality and estimated the financial implications for the services. Using the case of captive and non-captive public transport customers in South Africa, it was shown that perceived public transport service quality can increase service productivity, even with relatively low service ratings by the non-captive customers. Public transport services characterised by high proportions of captive customers in South Africa, with characteristically low cost recovery ratios would significantly benefit from improved service quality. The captive user base therefore remains an asset on which improvements should be made. It is for this reason that further research should develop improved methods for estimating the asset value of passenger trips (and satisfied customers), regardless of being from captive or non-captive customers, which could in turn find place in contract pre-planning.

\section{Appendix A. Supplementary data}

Supplementary data related to this article can be found at http://dx. doi.org/10.1016/j.retrec.2018.05.011.

\section{References}

Artis, A. B. (2004). A taxonomy of customer dissatisfaction-related coping tactics based on dissatisfaction-related goalsUnpublished PhD Thesis. Knoxville: University of Tennessee.

Bordagaray, M., dell'Olio, L., Ibeas, A., \& Cecín, P. (2014). Modelling user perception of bus transit quality considering user and service heterogeneity. Transportmetrica: Transportation Science, 10(8), 705-721.

Buckley, N. G. (2016). Sexual harassment on public transit and the influence of perceptions of safety on travel behaviorDissertation presented to the Faculty of the Graduate School of the University of Texas at Austin in Partial Fulfilment of the Requirements for the Degree of Master of Science in Community and Regional Planning. The University of Texas at Austin.

Cervero, R., \& Kang, C. D. (2009). Bus rapid transit impacts on land uses and land values in seoul. Working paperUC Berkeley Centre for Future Urban Transporthttps:// escholarship.org/uc/item/4px4n55x.

Currie, G., \& Stanley, J. (2008). Investigating links between social capital and public transport. Transport Reviews, 28(4), 529-547.

Department of Transport (DoT) (1998). Moving South Africa: Urban transport module (Project report. Pretoria, South Africa).

Department of Transport (DoT) (2006). The model tender and contract documents. Government gazette Notice 1058 of 2006. South Africa.

Fujii, S., \& Kitamura, R. (2003). What does a one-month free bus ticket do to habitua drivers? An experimental analysis of habit and attitude change. Transportation, 30, 81-95.

Garrett, M., \& Taylor, B. (1999). Reconsidering social equity in public transit. Berkeley Planning Journal, 13, 6 -27.

Grigoroudis, E., \& Siskos, Y. (2010). Customer satisfaction evaluation, international series in operations research \& management science, Vol. 139London: Springer Science \& Business Media, LLChttp://dx.doi.org/10.1007/978-1-4419-1640-2_1.

Grisé, E., \& El-Geneidy, A. (2017). Evaluating the relationship between socially (dis)advantaged neighbourhoods and customer satisfaction of bus service in London, U.K.
Journal of Transport Geography, 58, 166-175.

Gómez-Lobo, A. (2011). Monopoly, subsidies and the mohring effect: A synthesis and an extension. Chile: Department of Economics, University of Chile.

Hunter van Ryneveld (2014). Expenditure and review of South Africa's public transport and infrastructure system. Research conducted for the Presidency and National Treasury by Hunter van Ryneveld (Pty) Ltd, Pretoria, South Africa https://www.gtac.gov.za/ perdetail/Public\%20Transport\%20-\%20technical\%20report.pdf, Accessed date: 9 April 2018.

Ilieska, K. (2011). Knowledge for customer satisfaction - as a base for new strategic management. Škola biznisa, 144-156.

Jacques, C., Manaugh, K., \& El-Geneidy, A. M. (2013). Rescuing the captive [mode] user: An alternative approach to transport market segmentation. Transportation, 40(3), 625-645.

Kwan, S. J., \& Hashim, J. H. (2016). A review on co-benefits of mass public transportation in climate change mitigation. Sustainable Cities and Society, 22, 1 1-18.

Lowe, C. J. (2016). The social externalities of Australian bus and coach operators: How governance affects community prosperity PhD Thesis. Victoria, Australia: Monash School of Social Sciences, Faculty of Arts, Monash University Institute of Graduate Research, Clayton.

Marquez, L., Pico, R. \& Cantillo, V. (2018). Understanding captive user behavior in the competition between BRT and motorcycle taxis. Transport Policy, 61, 1 -9.

Mohring, H. (1972). Optmisation and scale economies in urban bus transportation. The American Economic Review, 62(4), 591-604.

Mokonyama, M., \& Venter, C. (2013). Incorporation of customer satisfaction in public transport contracts - a preliminary analysis. Research in Transportation Economics, 39, 58-66.

National Treasury (2017). budget review 2017. National Treasury republic of South Africa, pretoria, South Africa.

Orme, B. (1998). Sample size issues for conjoint analysis studies. Sawtooth software research paper series. Sequim WASawtooth Software, Inc.

Paulley, N., Balcombe, R., Mackett, R., Titheridge, H., Preston, J., Wardmand, M., et al. (2006). The demand for public transport: The effects of fares, quality of service, in come and car ownership. Transport Policy, 13(4), 295-306.

Pearce, D. W. (1978). The valuation of social cost. London, United Kingdom: George Allen and Unwin.

Ramaswamy, R. (1996). Design and management of service processes: Keeping customers for life. Engineering process improvement series. Massachusetts: Addison-Wesley Publishing Company, Inc.

Republic of South Africa (RSA) (2011). Consumer protection act, act 68 of 2008. Cape town, South Africa.

Rose, E., Racadio, R., Martin, T., Girard, D., \& Kolko, B. (2017). Expert yet vulnerable: Understanding the needs of transit dependent riders to inform policy and design. Journal of Community Informatics, 13(1), 3-24.

Rowley, C. (2005). The four Cs of customer loyalty. Marketing Intelligence \& Planning, 23(6), 574-581.

Stanley, J., Stanley, J., Vella-Brodrick, D., \& Currie, G. (2010). The place of transport in facilitating social inclusion via the mediating influence of social capital. Research in Transportation Economics, 29(1), 280-286.

StatsSA (Statistics South Africa) (2014). National household travel survey february to march 2013. Statistical release P0320, pretoria, South Africa.

Verbich, D., \& El-Geneidy, A. (2016). The pursuit of satisfaction: Variation in satisfaction with bus transit service among riders with encumbrances and riders with disabilities using a large-scale survey from London, UK. Transport Policy, 47, 64 -71.

Walker, J. (2008). Purpose-driven public transport: Creating a clear conversation about public transport goals. Journal of Transport Geography, 16(6), 436-442.

Walters, J. (2014). Public transport policy implementation in South Africa: Quo vadis? Journal of Transport and Supply Chain Management, 8(1), Art. \#134, 10 pages https:// doi.org/10.4102/jtscm.v8i1.134.

Wirtz, J., \& Bateson, J. E. G. (1995). An experimental investigation of halo effects in satisfaction measures of service attributes. International Journal of Service Industry Management, 6(3), 84-102. 